\title{
NOVA ESPÉCIE DE NIDULARIUMLEM. (BROMELIACEAE) PARA SÃO PAULO, BRASIL
}

\author{
Bianca Alsina Moreira ${ }^{1}$ \\ Maria das Graças Lapa Wanderley²
}

Recebido em 11/10/1999. Aceito em 27/01/2000

\begin{abstract}
Resumo - (Nova espécie de Nidularium Lem. (Bromeliaceae) para São Paulo, Brasil). No decorrer dos estudos das Bromeliaceae para a Flora Fanerogâmica do Estado de São Paulo, foi descoberta uma nova espécie do gênero Nidularium procedente da Serra da Bocaina. A descrição da nova espécie é acompanhada de ilustrações e de comentários.
\end{abstract}

Palavras chave - Nidularium, espécie nova, Bromeliaceae

\begin{abstract}
A New species of Nidularium Lem. (Bromeliaceae) from São Paulo State, Brazil). During the study of Bromeliaceae for the Phanerogamic Flora of the state of São Paulo, a new species of Nidularium from Serra da Bocaina was discovered. This paper presents description, illustration and comments about the new species.
\end{abstract}

Key words - Nidularium, new species, Bromeliaceae

\section{Introdução}

Como parte da monografia da família Bromeliaceae para a Flora Fanerogâmica do Estado de São Paulo, as autoras reconheceram uma nova espécie para o gênero Nidularium. Trata-se de uma planta epífita, procedente das Serras da Bocaina e da Mantiqueira, a uma altitude de ca. $1.500 \mathrm{~m}$. s. m., onde a mesma é freqüente, em Floresta Ombrófila Densa Montana na Serra do Mar. A espécie foi também encontrada em outras porções desta Serra, na Estação Biológica de Boracéia e no município de Lavrinhas, que abrigam uma rica porção da Floresta Atlântica.

Com base nos estudos realizados até o momento, o gênero Nidularium está representado na região por 4 espécies, incluindo esta nova espécie. Com a descoberta deste novo táxon, amplia-se para 22 espécies de Nidularium para o Estado de São Paulo.

\footnotetext{
1 Instituto de Botânica, C. Postal 4005, CEP 01061-970 São Paulo, SP, Brasil. E-mail: biancamoreira@yahoo.com
}

2 Instituto de Botânica. Bolsa de Produtividade em Pesquisa-CNPq. E-mail: gwanderley@smtp-gw.ibot.sp.gov.br 


\section{Descrição e discussão}

Nidularium longiscapum B. A. Moreira \& Wand., sp. nov.

Fig.1

Differt a Nidularium billbergioides (Schultes f.) L. B.var. billbergioides Sm. cui affinis et est: bracteis scapalibus 4-5; bracteis floriferis ad apicem roseum-purpuratis et carinatum; sepalis assymetricis ad apicem roseum; petalis in lobis cuculatis, purpuratis, ad basin 2 appendices; placentis medio affixix.
Epífita, 30-42,5cm alt.; rizomatosa. Roseta infundibuliforme, ca. 12 folhas; bainhas verdes a levemente arroxeadas, $10-12,5 \times 4,5-5 \mathrm{~cm}$, elípticas, papiráceas, esparsamente lepidotas em ambas as faces; lâminas verdes, 35,5-37×2,2$3,5 \mathrm{~cm}$, liguladas a lanceoladas, ápice acuminado, margem serrilhada, espinhos antrorsos. Escapo verde, ereto, longo, ca. $35 \mathrm{~cm}$, atingindo a altura das folhas ou pouco abaixo da roseta; brácteas do escapo 4-5, verdes, 4-16cm compr., mais longas até mais curtas que os entrenós, sendo as duas superiores menores

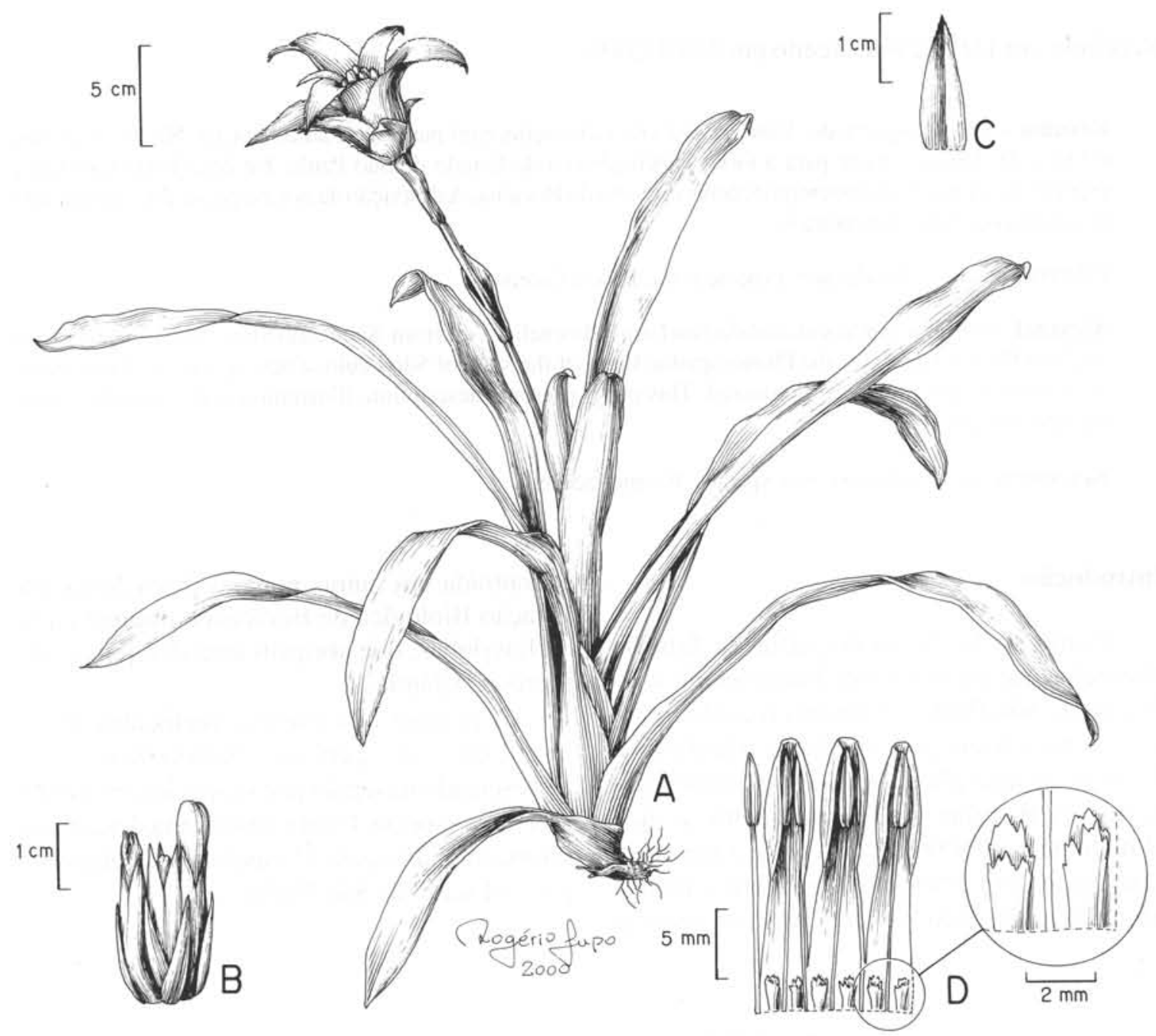

Figura 1. Nidularium longiscapum B. A. Moreira \& Wand.: a) hábito; b) fascículo; c) bráctea floral; d) corola aberta mostrando os estames epipétalos e com os detalhes dos apêndices basais. (Catharino s. n., SP340279). 
e na base da inflorescência, foliáceas, amplexescapo, as superiores ovadas, inferiores lanceoladas, ápice acuminado, lâmina com margem serrilhada, esparsamente lepidotas em ambas as faces. Inflorescência composta, capitada, 5,5-6,5×9-11 cm, fasciculada, cada fascículo com 3 flores, raque ca. $1 \mathrm{~cm}$ compr., raquilas $2-3 \mathrm{~mm}$ compr., com flores congestas; brácteas primárias papiráceas, verdes com ápice rosa a purpúreos, $8-4 \times 1,5-3,5 \mathrm{~cm}$, ovada, ápice acuminado e recurvado, margem serrilhada da metade até o ápice; bráctea floral alva, 1,3$2,5 \mathrm{~cm}$ compr., ovada, mais curta que as sépalas, ápice purpúreo, longo-atenuado e apiculado, carenado, reflexo, margem serrilhada em direção ao ápice. Flores róseas, sésseis, $2,9 \mathrm{~cm}$ compr.; sépalas alvo-esverdeadas, ápice purpúreo, $1,8 \mathrm{~cm}$ compr., lanceoladas, carenadas, assimétricas, conadas na base ca. $0,1 \mathrm{~cm}$, ápice agudo; pétalas rosas, $2 \mathrm{~cm}$, eretas, cuculadas, conadas apenas $0,3 \mathrm{~cm}$ compr., com 2 apêndices petalinos basais em forma de cálice e com ápice fimbriado, ca. $0,4 \mathrm{~cm}$ compr., duas calosidades ao longo dos filetes, entumecidos no ápice. Ovário trígono, $0,4 \mathrm{~cm}$ compr., placentação axial mediana. Fruto jovem ca. $1 \mathrm{~cm}$ compr.; sementes curto-caudadas.

Tipo: BRASIL: São Paulo: Bananal, Sede da Probocaina, Floresta Pluvial 1100 a $1500 \mathrm{~m}$, 10/VI/1995, fl. Catharino s. n. (SP340279), em cultivo no Bromeliário do Jardim Botânico de São Paulo (n. 540). (Holótipo SP, Isótipo RB). Parátipos: BRASIL: São Paulo: Biritiba-Mirim, Estação Ecológica de Boracéia, fl., 10 /VI/1984, Custodio Filho 2399 (SPSF); Lavrinhas, $12 \mathrm{~km}$ ao Norte de Lavrinhas, Vale do Ribeirão do Braço, fr., 6/IV/1995, Kinoshita \& Moreira $9520(\mathrm{SP})$.
O epíteto específico longiscapum refere-se à presença de escapo longo, projetando a inflorescência desde a parte mediana até o ápice da roseta. Destaca-se também nesta espécie as brácteas primárias esverdeadas com ápice róseo e pétalas purpúreas com a presença de apêndices basais, o que a diferencia essencialmente de $N$. billbergioides (Schultes f.) L. B. Sm. var. billbergioides, cujas brácteas primárias são amarelas ou avermelhadas, com pétalas alvas, ápice cuculado e agudo e sem apêndices. Estes apêndices estão em geral ausentes no gênero Nidularium, mas foram observados em outras espécies, como em $N$. minutum Mez, transferida para Wittrockia por Smith (1952) por possuir estas estruturas. No entanto, assim como a nova espécie aqui descrita, ambas pertencem ao gênero Nidularium.Desta forma é aqui proposta a revalidação de $N$. minutum $\mathrm{Mez}$, considerando este caráter pouco consistente para separar os dois gêneros.

\section{Agradecimentos}

Ao pesquisador Eduardo Luís Martins Catharino pela coleta do material estudado.

\section{Referências bibliográficas}

Leme, E. M. C. 1998. Canistropsis. In: M. V. Pereira (Ed.) Bromélias da Mata Atlântica. Salamandra, Rio de Janeiro.

Smith, L. B. 1952. Bromeliáceas novas ou interessantes do Brasil -V. Arquivos de Botânica do Estado de São Paulo 2(6): 197.

Smith, L. B. \& Downs, R. J. 1979. Bromelioideae (Bromeliaceae). In: Flora Neotropica 14(3): 1493-2142. 